\title{
Knowledge of nurses towards dengue fever in a tertiary care teaching hospital in Nepal
}

\author{
S Valarmathi, ${ }^{1}$ S Parajulee ${ }^{2}$
}

${ }^{1}$ Lecturer, Nursing program, ${ }^{2}$ Chief of Nursing program, College of Medical Sciences, Bharatpur, Nepal

\section{Abstract \\ Background}

Nurses are important health care professionals and should have wide knowledge about common diseases especially infectious diseases like dengue. Dengue is associated with shock and can lead to death.

\section{Aim}

To assess the knowledge of nurses regarding dengue fever and to study the association between the demographic variables.

\section{Setting and design}

A cross sectional study was conducted at the College of Medical Sciences-Teaching Hospital, Nepal among the nurses during December, 2010.

\section{Study tool}

Semi structured question was prepared to assess the knowledge of nurses in which there was objective question and Yes or No type questionnaire.

\section{Statistical analysis}

The filled questionnaires were collected and data were entered in Microsoft excel sheet and analyzed as per study objectives. Descriptive statistic was used to calculate the median (IQR) and non parametric tests (Kruskal Wallis test and Mann Whitney test) to compare the total scores with demographic profile of the subjects.

\section{Results}

Of the study members $89 \%$ were from Proficiency Certificate level (PCL) background and the mean (IQR) age of the respondents was 21 years (20-22.75). Overall score of the nurses was 11 (9-13) with a maximum possible score of 17 . There were no association between the respondents knowledge scores with age $(p=0.14)$; educational qualifications $(p=0.86)$; duration of experience $(p=0.59)$; ward $(p=0.28)$.

\section{Conclusion}

The study findings report a low knowledge among the nursing practitioners on dengue fever and its complications and their knowledge did not have any association with their demographic variables.

\section{Key words: Dengue fever, knowledge, Nepal, Nurses.}

Correspondence: Ms. S. Valarmathi

Email: valarmathisubish@gmail.com 


\section{Introduction}

Nurses play an important role in health care system in both institutionalized settings and community care centers. In a hospital nurses come across various types of patients. So the nurse should have wide knowledge about all diseases especially infectious diseases like dengue fever, one of the most important tropical diseases of humans in the world. As per the Centers for Disease Control and Prevention (CDC), USA, more than one-third of the world population living in areas with risk of transmission of dengue and dengue infection is known to be a leading cause of illness and death in the tropical and subtropical countries. ${ }^{1}$ It is estimated that there are between 50 and 100 million cases of dengue fever and about 500000 cases of dengue hemorrhagic fever each year leading to hospitalization. ${ }^{2,3}$ Over the last 10-15 years dengue fever has become a leading cause of hospitalization and death among children in south east Asia region of World Health Organization. ${ }^{2}$ It is not clear regarding the precise year in which Dengue was first reported in Nepal, but sporadic cases were reported in foreigners visiting Nepal in the late 90s and the year 2004. ${ }^{4}$ It is expected that during monsoon and post monsoon season dengue transmission will recommence and major outbreaks could occur causing high morbidity and over whelming the health care system.

There has been a rise in the number of dengue cases in the country and has been considered as an emerging health problem. One study found that dengue has substantial expansion in Western and Far Western Terai region of Nepal which was limited to the middle Terai region in the past and mostly infects older people. ${ }^{5}$

One study suggested that serological marker can be used to diagnose acute patients of dengue during outbreaks. ${ }^{6}$ Having adequate knowledge can help the nurses in providing health education to general public and patients thus helping in minimizing the occurrence of dengue. So far there has been no study from Nepal evaluating the knowledge of nurses on this infection. This present study aims at evaluating the knowledge of nurses in a tertiary care teaching hospital located in central part of the Nepal and a dengue prone district of the country. Understanding the nurses knowledge might help in identifying the requirements for training the nurses in this disease. Hence this research has been carried out.

\section{Objectives}

The present study had the following objectives.

1. To assess the knowledge of nurses towards dengue fever.

2. To study the association between the knowledge scores of the nurses with their selected demographic variables

\section{Methodology}

Study design: A cross sectional study evaluating the knowledge of the nurses regarding dengue fever.

Study site: College of Medical Sciences-Teaching Hospital (CMS-TH), a 900 bedded tertiary care teaching hospital with various specialty and super specialty departments.

Study subjects: The subjects were the nurses working in various departments. They have either a PCL (Proficiency certificate level) nursing or B.Sc (N) Bachelor of Science in Nursing.

Inclusion and exclusion criteria: All the nurses who were on duty during the study period were enrolled. The ones on leave were excluded from the study. 
$S$ Valarmathi et al, Khowledge of nurses towards dengue fever.

Study tools: A self designed questionnaire was used in the study. The questionnaire had 17 questions. This questionnaire was developed by the researchers in consultation with an expert in scientific research. The face and content validity was carried out through discussion among the researchers and the expert.

Method of data collection: The researchers personally went to the work station of the study subjects and got the questionnaire filled by the nurses. Adequate time (nearly 30 minutes) was given to each respondent for filling the questionnaire.

Data analysis: The filled questionnaires were collected and the data were entered in Microsoft Excel spread sheet and were analyzed as per the study objectives. The correct answers were given a score of ' 1 ' and wrong answers were given a score of ' 0 '.

Statistical analysis: The SPSS Version 16 was used to carry the statistical analysis. Median and interquartile range were carried out for the demographic variables and Kruskal Wallis test and Mann Whitney tests were used to compare the median scores with the respondent's demographic variables.

\section{Results}

Altogether 100 nurses (89 from PCL Nursing and 11 from B.Sc Nursing) were enrolled in the study. Median (IQR) age of the respondents was 21 (20-22.75) years. Further details on the demographic distribution of respondents are listed in Table 1.

Table 1. Demographic distribution of the respondents $(n=100)$

\begin{tabular}{llcc}
\hline Parameters & \multicolumn{1}{c}{ Interval } & Number & Percentage \\
\hline Age (in years) & Less than 20 & 5 & 5 \\
Median (IQR) age $=$ & $20-25$ & 91 & 91 \\
21 (20-22.75) & $26-30$ & 4 & 4 \\
Educational & More than 30 & 0 & 0 \\
Qualifications & PCL & 89 & 89 \\
Duration of experience & B.Sc (N) & 11 & 11 \\
(in months) & Up to 12 months & 62 & 62 \\
& 13-24 months & 34 & 34 \\
Ward & More than 24 months & 4 & 4 \\
& Pediatrics & 10 & 10 \\
& Medical ward & 10 & 10 \\
& Neurosurgery & 8 & 8 \\
& Neonatal intensive care unit & 8 & 8 \\
& Neurology & 8 & 8 \\
& Intensive care unit & 8 & 8 \\
& Operation theatre & 7 & 7 \\
& Surgery & 7 & 7 \\
& Orthopedics & 7 & 7 \\
& Private ward & 6 & 6 \\
& Causality & 6 & 6 \\
& Urology & 5 & 5 \\
& Obstetrics and Gynecology & 3 & 3 \\
& Cardiology & 3 & 3 \\
& Hemodialysis & 2 & 2 \\
& Emergency & 1 & 1 \\
\hline
\end{tabular}


Comparison of respondents' total score with demography

The median (IQ range) total scores of the respondents were compared with their selected demographic parameters. Overall score of the nurses was 11(9-13).
The results revealed no association between the respondents knowledge scores with age $(\mathrm{p}=0.14)$; educational qualifications $(\mathrm{p}=0.86)$; duration of experience $(\mathrm{p}=0.59)$; ward $(\mathrm{p}=0.28)($ Table 2$)$.

Table 2. Total scores of the respondents with demographic variables

\begin{tabular}{lccc}
\hline Parameters & Interval & Median (IQ range) & P Value \\
& Less than 20 & $11(9.5-14.5)$ & 0.14 \\
Age & $20-25$ & $11(9-13)$ & \\
& $26-30$ & $8.5(4.25-10.5)$ & 0.86 \\
Educational qualifications & PCL & $11(9-13)$ & 0.59 \\
& BSc & $10(11-14)$ & \\
Duration of experience & Up to 12 months & $11(8.75-13.25)$ & \\
& $13-24$ months & $11(10-13)$ & 0.28 \\
Ward & More than 24 months & $12.5(9-13)$ & \\
\hline
\end{tabular}

\section{Responses of the nurses to individual statements}

Attempt has been made to analyze the individual responses provided by the nursing practitioners (Table 3). It was found that $86 \%$ of the nurses knew the cause of dengue fever to be 'virus' (Q.No 1) and 98\% of the respondents knew the spread of dengue fever through 'mosquitoes' (Q.No 2). It was found that only $52 \%$ of the respondents knew the other name of dengue fever as 'Hemorrhagic fever' (Q.No 6). It was found that only less than one third (31\%) of the nurses has received in-service training regarding any infectious disease in the past (Q.No15). 
$S$ Valarmathi et al, Khowledge of nurses towards dengue fever.

Table3.Responses of the nurses to individual statement

\begin{tabular}{|c|c|c|c|}
\hline Q.No. & Numbe & $\begin{array}{l}\text { er of respondents } \\
\text { answered } \\
\text { correctly }\end{array}$ & $\begin{array}{l}\text { Percentage of } \\
\text { respondents } \\
\text { answered correctly }\end{array}$ \\
\hline 1. & Dengue fever is caused by & 86 & 86 \\
\hline 2 & Dengue fever is spread by & 98 & 98 \\
\hline 3 & Are you aware of any dengue epidemic & & \\
\hline & in Nepal? & 73 & 73 \\
\hline 4 & Are you aware of any symptoms of dengue fever? & 84 & 84 \\
\hline 5 & $\begin{array}{l}\text { Please mention the diagnostic tests involved in } \\
\text { diagnosing dengue fever }\end{array}$ & 82 & 82 \\
\hline 6 & $\begin{array}{l}\text { One of the following is the other name of dengue } \\
\text { fever? }\end{array}$ & 52 & 52 \\
\hline 7 & $\begin{array}{l}\text { The more vulnerable group of population for dengue } \\
\text { fever is }\end{array}$ & 38 & 38 \\
\hline 8 & The incubation period of dengue fever is & 54 & 54 \\
\hline 9 & The major complication of dengue fever is & 58 & 58 \\
\hline 10 & Normally a dengue outbreak occur during & 54 & 54 \\
\hline 11 & $\begin{array}{l}\text { One of the medications may be harmful in patients } \\
\text { suffering from dengue fever }\end{array}$ & 65 & 65 \\
\hline 12 & $\begin{array}{l}\text { Do you think dengue fever can be spread from one } \\
\text { individual to another? }\end{array}$ & 80 & 80 \\
\hline 13 & $\begin{array}{l}\text { Do you think dengue fever can spread by sharing } \\
\text { utensils and clothes of an infected individual? }\end{array}$ & 73 & 73 \\
\hline 14 & $\begin{array}{l}\text { Have you gathered any information regarding } \\
\text { dengue fever in the recent past? }\end{array}$ & 42 & 42 \\
\hline 15 & $\begin{array}{l}\text { Have you received any in-service training regarding } \\
\text { any infectious disease }\end{array}$ & 31 & 31 \\
\hline 16 & $\begin{array}{l}\text { Do you think any socioeconomic factors can } \\
\text { predispose an individual to dengue fever? }\end{array}$ & 68 & 68 \\
\hline 17 & $\begin{array}{l}\text { Have you come across any individuals suffering } \\
\text { from dengue fever? }\end{array}$ & 46 & 46 \\
\hline
\end{tabular}

Note: Total number of respondents is 100 


\section{Discussion}

The present study assessed the knowldge of nurses towards dengue fever. Overall score of the nurses was 11 (9-13) out of the maximum possible score 17. This suggests a poor knowledge regarding dengue fever among the nurses. Our finding is in agreement with the finding of researchers from Taiwan where the nurses and other health professionals usually possessed a low knowledge. ${ }^{6}$

The study findings suggest that many of the nurses were aware of the cause and spread of dengue fever. Similarly, the nurses were known to have a good knowledge on the symptoms exhibited by dengue fever and also on the epidemic on dengue that occurs in Nepal. During August 2010 it was reported that in Chitwan district alone, where the study has been conducted 24 people have died due to this dreadful disease. $^{7}$

The nurses also had a good knowledge on diagnostic tests involved in dengue fever diagnosis. However the knowledge of nurses on more vulnerable group of population for dengue fever is quite low.

It was also found that less than half of the nurses have ever gathered any information regarding dengue fever in the recent past. This showed a poor practice among nurses on updating their knowledge which is again linked to their poor knowledge and awareness regarding an important disease.

Similarly, only less than one third of the nurses under study have ever received any in-service training regarding any infectious disease. This may be reason for nurses to possess a poor knowledge on dengue fever.

It is a hard fact that the nurses whom themselves do not know the causes and prévention of dengue fever will not be able to educate the patients in a better way. To be in a position to educate the patients, the nurses should possess adequate knowledge and skills. The demography of the respondents did not have any major impact on the knowledge score. The finding signifies the need for educational interventions for all the category of professionals. Although every nursing practitioner needs training, they should be categorized based on their educational qualifications since there were variations in the knowledge levels between nurses with different qualifications.

The major limitation of the study was that only 100 nurses were enrolled in the study and hence the findings may not be generalized to the entire hospital.

\section{Conclusions}

The study findings suggest the need for a formal health teaching programme and reinforcement of the program so as to improve the knowledge of the nursing practitioners. It would be also benefit to have continuing nursing education programs for the nursing practitioners.

\section{Acknowledgements}

The Authors acknowledge all the Nursing staffs who spent their valuabe time in responding to our request. 
$S$ Valarmathi et al, Khowledge of nurses towards dengue fever.

\section{References}

1. Dengue Centers for Disease Control and Prevention. Available at http://www.cdc.gov/ dengue/

2. Dengue and Severe dengue. World health Organization, 2012. Available at http:// www.who.int/mediacentre/factsheets/fs117/en/

3. Prasittisuk C, Andjaparidze AG, Kumar V. Current Status of Dengue/Dengue Haemorrhagic Fever in WHO South-East Asia Region. Dengue Bulletin 1998; 22: 1-107.
4. Shah Y, Katuwal A, Pun R, et al. Dengue in Western terai region of Nepal. J Nepal Health Res Counc. 2012 May; 10(21):152-5.

5. Pun R, Pant KP, Bhatta DR, et al. Acute dengue infection in the western terai region of Nepal. JNMA J Nepal Med Assoc. 2011; 51(181):11-4.

6. Huang HL, Chiu TY, Huang KC et al. Travelrelated mosquito-transmitted disease questionnaire survey among health professionals in Taiwan. $J$ Travel Med. 2011;18(1):34-8.

7. Sharma SP. Dengue outbreak affects more than 7000 people in Nepal. BMJ 2010; 341:c5496. 